\title{
PHYSICAL ACTIVITY AS A PART OF CHILDREN'S QUALITY OF LIFE MODEL
}

Prof. Ph.D. Monica STĂNESCU,Prof. Ph.D. Luican HOINY, National University of Physical Education and Sport, Doctorate School, Bucharest, ROMANIA,

E-mail: monica_iulia@yahoo.com

\begin{abstract}
Research on children's quality of life is largely attributed to adults' needs or perceptions of children's quality of life. Child well-being was initially assessed in terms of objective reality: mortality rates, malnutrition, immunisation, disease, with little reliability in measuring their subjective well-being. Subjective quality of life refers to perceptions, aspirations, assessment of one's own living conditions. A holistic model of children's quality of life involves measuring the economic, social, physical, psychological and cognitive dimensions using instruments that reveal the subjective view of their quality of life. The aim of this paper is to examine the multidimensional nature of children's quality of life and to identify the place of physical activity in the quality of life (QoL) model. Physical activity is associated with higher quality of life. Research on children's quality of life through interventions that use physical activity primarily reflects an intervention-based model for disease prevention or mitigation. A QoL model using physical activity interventions may also have some limitations, unless it assumes the measurement of other domains that may influence it. Children's quality of life is a relatively new topic in the literature. Although many models of children's quality of life are proposed, a unified model has not been agreed upon by experts. Measuring it requires the use of instruments for each dimension of which it is composed. Physical activity as a method of intervention on children's quality of life is associated with children's physical as well as psychological well-being.
\end{abstract}

Keywords: children's quality of life; physical activity; subjective well-being;

\section{INTRODUCTION}

Quality of life (QoL) is a multidimensional concept consisting of general well-being, which encompasses objective factors as well as subjective assessments of physical, material, social and emotional well-being. Children's quality of life was initially studied in objective terms such as mortality rates, immunisation, malnutrition, disease. Research in the field of quality of life has led to the differentiation between children's and adults' quality of life. Children think differently, act differently, their perceptions of life satisfaction are different, and these issues have resulted in the development of indicators, measures and assessments of QoL in line with the child's developmental level.

Although the positive effects of regular physical activity are well known and physical activity is associated with improved psychological well-being, the physical dimension, a component of quality of life, is associated and studied in terms of health or disease prevention.

Research purpose

This paper aims to examine the multidimensionality of children's quality of life, establishing the place of physical activity in the children' quality of life model. 


\section{TOPIC ADDRESSED}

The concept of quality of life

The concept of quality of life emerged in the late 1960s (Noll, 2002) as an alternative to society's goal of increasing material standards at that time. In addition to the material conditions that make up society's well-being, the concept also encompasses the immaterial conditions of life such as health, social relations and environmental quality.

From a European perspective, according to Eurostat (European Union, 2015), quality of life refers to the well-being of people in society, including material conditions, health, housing, work, family life, work-life balance, subjective well-being and the relationship of the individual with the society in which they live.

The World Health Organization defines quality of life as "individuals' perception of their position in life in the context of the culture and value systems in which they live and in relation to their goals, expectations, standards and concerns" (The WHOQOL Group, 1995, p. 1403). It is a broad concept that affects physical and mental health, personal beliefs, social relations and the relationship with the environment in a complex way.

\section{Multidimensional aspects of quality of life}

Quality of life has been conceptualised as: multidimensional (being influenced by personal and environmental factors and their interactions); having the same components for all people; consisting of subjective and objective components; being enhanced by selfdetermination, resources, purpose in life and a sense of belongingness (Cummins, 2005).

Objective living conditions include living standards, working conditions or health status, while subjective well-being includes cognitive and affective components. The typology of welfare positions proposes four groups of objective living conditions and subjective well-being. The relationship between good living conditions and positive subjective perception is called well-being. The relationship between good living conditions and negative subjective well-being is perceived as dissonance. Poor living conditions in cohesion with a low level of subjective well-being is seen as deprivation. Poor living conditions in cohesion with high subjective well-being is described as adaptation. (Zapf, 1984, cited by Noll, 2002; Noll, 2013)

Scientific analysis of subjective well-being refers to how people assess their lives both at the moment and for longer periods, for example, the previous year. Such assessments include people's emotional reactions to events, their moods and judgments about life satisfaction. (Diener et al., 2003)

Cummins (2005) describes five essential characteristics of quality of life. The author highlights as a first characteristic two different forms of QoL: objective, which can be observed and measured within the public domain, and subjective, which exists only in the consciousness of each individual and is verified only through repeated responses provided by the individual. A second characteristic involves measuring the quality of life in any overall determination from objective and subjective perspectives, given that both are valid indicators of quality of life. The third characteristic refers to the basic components of the concept, which should be the same for all people, with variations according to the components valued by the individual due to cultural and socioeconomic differences. A common core with basic elements of quality of life for all people suggests the idea that a QoL measure can be created and validly used for any human group regardless of culture, socioeconomic level, status or disability. The fourth characteristic involves defining QoL in terms of needs; low levels of need are indicators of deprivation. Quality of life should not be seen in terms of opportunity. 
The fifth characteristic supports the idea that opportunities can also be viewed negatively by a person and that the experience of opportunity for QoL is more likely a causal variable, not the end state or outcome.

The concept of quality of life included the absence of negative aspects of life as well as positive aspects (Cummins 1995, 1998, 2000, cited by Casas, 2011). Quality of life addressed the traditional concepts of positive social change to which psychosocial factors, especially personal well-being, were added.

The QoL study supported the idea that we should only intervene when things were not going well. If there were no problems, people thought they should not intervene to change anything. The concept of prevention (Caplan, 1964 cited by Casas, 2011) has raised a question mark, supporting the reasoning that there is a possibility that things may be going in the wrong direction and that intervention should take place before a problem arises.

This concept has led to a new way of thinking about how the intervention would take place to improve social conditions even if they seem unlikely to deteriorate. The intervention considered good for everyone can also take place before a problematic situation occurs. This new logic of thinking has resulted in the emergence of health promotion programmes, followed by welfare and quality of life promotion programmes. All of this has shifted the focus from facing and overcoming social problems to promoting quality of life.

\section{Addressing quality of life}

The approach to health-related quality of life involves aspects such as perceived wellbeing in the physical, mental and social domains or how well a person functions in life. Functioning refers to an individual's ability to perform some predefined activities, while well-being refers to an individual's subjective perceptions.

Another approach to health-related quality of life includes only those factors that are part of an individual's health domain. Some aspects of quality of life, for example, economic and political circumstances, are not included in this perspective. Defining quality of life through the lens of health focuses on those aspects of quality of life that are affected by health, for instance, those aspects of well-being that are related to or affected by the presence of disease or treatment.

\section{Children's quality of life}

Research on children's quality of life is largely attributed to adults' needs or perceptions of children's quality of life. This approach (Casas, 2007) overlooks the basic definition of the concept: people's own perceptions, assessments and aspirations regarding their subjective well-being. Research on children's quality of life is not really about their quality of life but about other people's opinions or perceptions of their lives.

Young people and adults see themselves as members of different social groups or categories. Young people give importance to new and fun experiences, discovering their limits or taking risks, while for adults, safety is much more important, which can lead to the perception that adults want to control young people's lives and limit their freedom.

Child well-being was initially assessed in terms of objective reality: mortality rates, malnutrition, immunisation, disease, etc. In addressing children's quality of life, one should take into account aspects such as: children's living conditions; their perceptions, assessments and aspirations regarding their own lives - including subjective well-being; the perceptions, assessments and aspirations of other relevant social agents regarding children's lives and 
living conditions, i.e., those of parents, teachers, paediatricians, educators, social professionals.

A review of the 1991-1999 literature on child welfare (Pollard \& Lee, 2002) identifies five domains of well-being: physical, psychological, cognitive, social and economic. The social domain includes only social aspects. The psychological domain includes indicators that relate to emotions, mental health or mental illness. The cognitive domain refers to intellectual or school-related aspects. The indicators for each domain are divided into positive and negative clusters. The physical, economic, cognitive and social domains tend to measure positive aspects of well-being, while the psychological domain is oriented towards measuring the current deficit in well-being.

Measures of children's objective well-being range from analysis of school data, medical history, national statistics on delinquency to the use of banned substances. Subjective assessment includes indicators such as self-esteem or depression, which leads to some limitations because well-being manifests itself in several dimensions; therefore, assessing only one dimension of well-being does not reveal the other domains that may influence it. In the review by Pollard and Lee (2002), it has been found that most researchers measure only one domain of children's well-being and that only $2.3 \%$ of the articles studied by the two authors measure cognitive, physical, psychological and social well-being.

For each domain, instruments were used to measure psychological well-being (selfesteem, depression, anxiety, general well-being). The social level was assessed by measuring indicators such as family, friends, emotional support, personal resources, communication skills, social role models. The cognitive domain was assessed by academic levels and intelligence tests as well as creativity, behaviour at school, children's own perspective on their satisfaction with the academic environment; the cognitive domain also included assessments made by parents and teachers about their perception of children's school performance. The economic domain was assessed using indicators such as family resources or parental income. The physical domain was assessed by physical health. All these measures included tests to assess physical fitness, participation in physical activity as well as knowledge about physical condition (fitness) and nutrition. Negative variables that pose a health risk, such as smoking or use of banned substances, were also included.

Quality of life indicators for children aged 8-13 and 11-19 by domain are expressed in positive and negative terms (Pollard \& Lee, 2002):

- cognitive (negative) academic, concentration, developmental delays, school problems;

- cognitive (positive) school success, cognitive skills, quality of school life, school integration, attitudes in the school environment, self-concept of academic skills;

- economic (negative) social assistance (child support);

- economic (positive) social assistance (child support);

- physical (negative) health-compromising behaviour, physical abuse, physical manifestations of stress, physical manifestations of illness, substance abuse, use of prohibited substances;

physical (positive) exercise, health-promoting behaviour, nutrition, personal hygiene, physical appearance, physical health, attitude to safety, well-being;

psychological (negative) adjustment problems, aggression, anger, anxiety, behavioural problems, delinquency, depression, hopelessness, deviant behaviour, distress, nutritional problems, emotional problems, fear, fear for the future, general psychological distress, health-compromising behaviour, hopelessness, hyperactivity, impaired concentration, inattention, irritability, loneliness, maladjustment, negative affect, neuroticism, 
nervousness, nightmares, panic, psychiatric symptoms, psychological health symptoms, recurrent memories of self-harm, egocentricity, self-harm, malice, stress, suicidal intent, etc.; psychological (positive) adaptation, attachment, autonomy, behavioural skills, ability to love, cheerfulness, ability to cope with different situations, emotional support, emotional regulation, expansiveness, success-oriented thinking, fulfilment, general satisfaction, happiness, hope, initiative, satisfaction with life, mental health, positive school attitude, positive attitude towards self, purpose in life, positive states, self-concept, selfesteem, self-identified strengths, self-confidence, self-worth, socio-emotional regulation, well-being, stress management;

- $\quad$ social (negative) anti-social, negative life events, problems relating to others, poverty, problems in family life;

- $\quad$ social (positive) relationship between family members, participation in cultural events, social values, social behaviour, quality of life, relationship with family, school, other members of society, social acceptance, social skills, social support, socioeconomic status, well-being.

In determining holistic child well-being after a critical review of international models, Marjanen et al. (2017) selected four models that they considered the most cited or referred to when discussing child well-being and its measurement. Following the selection of models, namely The State of the World's Children 2014 (UNICEF, 2014), The Child Development Index (CDI, 2012), Doing Better for Children (OECD, 2009) and The Holistic Early Childhood Development Index (HECDI, 2014), the authors presented key international indicators used to measure child well-being.

Marjanen et al. (2017) believe that the UNICEF child well-being model (2014) is comprehensive and addresses many necessary issues; however, the authors are unsure whether categories such as subjective well-being, risk behaviours, family relationships, civic participation and inequality are sufficiently addressed through this model. The indicators used in the child well-being model (2014) are broad, such as women, adolescents, child protection and rate of progress, but the specific indicators reflected within these categories are somewhat limited and imply a strong deficit, vulnerability and a development-oriented approach. The organisation was criticised for neglecting to include indicators on children's subjective well-being in its data.

The Child Development Index (2012) focuses exclusively on three broad indicators: health, nutrition and education. This model is considered by Marjanen et al. (2017) to be limited in terms of indicators and therefore does not reflect a holistic approach to well-being; besides, it does not sufficiently allow for an understanding of a child's will, in other words, its subjective measurement.

The OECD report (2009) differs from the previous two models in that, while focusing primarily on political economy approaches, it incorporates elements such as reflections on the quality of school life, indicators of bullying in schools, children's school satisfaction levels and political and social spending on families and children. They also included indicators on risk behaviours as a separate category to be measured (e.g., smoking, teenage births) in determining child vulnerability and well-being. As Marjanen et al. (2017) said in the review of the literature, the first two models omitted the inclusion of subjective measures.

The Holistic Early Childhood Development Index (2014), despite its progress in measuring holistic child well-being, is seen as being mainly based on economic and statistical measures, with limited subjective indicators to determine holistic child well-being. 
Analysing existing models of children's quality of life in international research, Petelewicz (2015) proposes a model that includes: Living Conditions, Family Relationships, Friendship Relationships, School, Health, Subjective Well-being.

Analysed models (Petelewicz, 2015): Innocenti Research Centre (UNICEF) model, Child Well-Being Index (CWI) (Land et al., 2007), EU-25 Child Well-Being Index (Bradshaw et al., 2007), The State of London's Children (SOLC) reports (Hood, 2007), Comprehensive Quality of Life Scale - School Version (Cummins, 1997), The Multidimensional Life Satisfaction Scale (Cummins, 1997).

Cummins et al. (2005) developed a framework of subjective well-being consisting of nine domains: standard of living, health, life achievement, relationships, safety, community connectedness, security, religion/spirituality, school.

\section{Physical activity and quality of life}

The positive effects of regular physical activity are widely recognised and highlighted in numerous scientific studies. Physical inactivity or inactivity is a risk factor for cardiovascular and other chronic conditions, including diabetes, cancer (colon and breast), obesity, high blood pressure, bone and joint diseases (osteoporosis and osteoarthritis). Physical activity is also associated with improved psychological well-being (e.g., by reducing stress, anxiety and depression). A number of studies have shown that exercise can play a therapeutic role in addressing a number of psychological disorders (Mountjoy et al., 2011; Biddle et al., 2019; Kirkcaldy et al., 2002). Evidence of the health benefits of physical activity mainly focuses on physiological, cognitive and affective benefits, which do not exclude social and interpersonal benefits Physical activity is associated with improved quality of life. The clear relationship between them can be expressed in the health benefits of physical activity. The IOC (International Olympic Committee) brought together a group of experts (2007-2011) to discuss the role and benefits of physical activity, sport and physical education for the health of young people. The expert group conducted a critical assessment of the scientific evidence as a basis for policy makers to identify potential solutions for collaboration between the sport sector and existing programmes and to review research gaps in this area. The paper also provides recommendations on physical activities for young people and other stakeholders in the sector (NGOs, research, governments, etc.).

Following a review of the literature, Mountjoy et al. (2011) identified several health consequences of the lack of physical activity, physical education or sport. The review of the papers concluded that a 30-minute intervention carried out three times a week, at a sufficient intensity to develop aerobic capacity, could reduce blood pressure in young people with hypertension. Studies (Bell et al., 2007; Janssen \& LeBlanc, 2010) on blood lipid levels demonstrate that interventions including aerobic training, resistance training and circuit training performed for a minimum of 40 minutes per day, five days per week and lasting at least 4 months can lead to improvements in lipid and lipoprotein levels. The literature suggests that low levels of physical activity in young people are associated with higher levels of obesity, hypertension and cardiovascular risk factors. The bone mass of participants in weight-bearing physical activity is increased compared to non-athletes (Vicente-Rodriguez et al., 2003). Racquet sports players who started training at the onset of puberty have significantly stronger bones on their playing arm (Kannus et al., 1995) compared to the other arm, and the benefits persist over time. During puberty, bones are still forming, which allows their strengthening. However, the bone response to exercise depends on the young person's 
gender and maturity level, the measured anatomical site, the duration and intensity of the intervention.

Physical activity and sport during growth and development are associated with numerous health benefits, including low levels of overweight and obesity and reduced risk of obesity in adulthood. Although much research suggests young people's participation in organised or leisure sports, physical activity has declined in recent decades. A balanced diet and exercise are important factors that contribute to maintaining weight and body composition.

Mountjoy et al. (2011) found little evidence from a review of existing research on the beneficial effects of physical activity on reducing depression and anxiety. Depression, anxiety, self-esteem and cognitive performance in children are most commonly studied when talking about mental health and its improvement through physical activity. An updated review (Biddle et al., 2019) of studies on physical activity and mental health in children and adolescents found that their effects on reducing anxiety ranged from moderate (for youth with ADHD) to high (for youth without health or mental health problems). Therefore, the effects of physical activity on reducing depression are small, and the reason could be, as Biddle et al. (2019) say, the lack of adequate measurements or study of its effects on a healthy population. Self-esteem is a complex field, and defining it requires the inclusion of the subdomains of which it is composed, such as physical and social self-perception (Biddle et al., 2019).

In this ambiguous context of defining self-esteem by authors in their research, Biddle et al. (2019) have concluded that the association between physical activity and self-esteem in young people is not causal. Physical activity in various forms has positive effects on the cognitive domain (Biddle et al., 2019), which can relate to cognitive function, academic achievement, brain structure and function. The authors have found sufficient evidence to suggest and support the view that physical activity is beneficial for cognitive function and performance in young people, with references to executive functioning and memory, including the neural networks that support executive functioning (initiation, adaptation, regulation, monitoring and control of information processes and behaviour).

The approach to quality of life in conceptualisation and measurement attempts can be categorised by the first of three distinct approaches: health-related quality of life, social indicators and subjective well-being. The concept of quality of life expressed in terms of health was developed to capture aspects of an individual's subjective experience related to both illness, disability, disorders and the effects of medical treatment. (Wallander \& Koot, 2016)

Purely objective measures are used to assess social indicators. An example of an objective measure of children's quality of life is infant mortality, which might be reduced but this would require very high medical expense as well as a higher number of surviving children with severe disabilities (Diener \& Suh, 1997).

Other examples of objective indicators: standard of living, immunisation, access to health services, etc. Purely objective measures do not provide adequate information about children's quality of life; defining quality of life involves assessing subjective experience, taking into account children's views on their quality of life.

Subjective quality of life measures allows the assessment of quality of life from children's perspective taking into consideration individual values and preferences. They can 
provide information about individuals and groups of people, which is important for policy makers and the general public.

Few studies have paid specific attention to the link between quality of life and children's participation in physical activity. Interventions on children's quality of life are measured in terms of health and associated with improved quality of life. A study (Vella et al., 2014) that examined the relationships between one or more specific characteristics of sport participation and quality of life in terms of children's health found that children performing team sports or team sports and individual sports had a more favourable quality of life compared to children participating only in individual sports and children not participating in sports.

Moeijes et al. (2019) showed that sports club membership as well as highly active children compared to children less involved in sports activities had significantly better quality of life, with prominent differences in the physical and social domains but to a lesser extent in the psychological domain. The above authors did not observe any significant differences between highly active and moderately active children in terms of sport. No significant differences were noticed between moderately active and less active children, except for the dimensions of physical well-being and social acceptance, with moderately active children having a better quality of life. Also, few significant differences in health-related quality of life were observed between children playing individual sports, children playing team sports and children playing both individual and team sports. Participation in outdoor sports was significantly associated with improved quality of life compared to participation in indoor sports.

\section{CONCLUSION}

Children's quality of life is a relatively new topic in the literature. Although many models of children's quality of life are proposed, a unified model has not been agreed upon by experts. Measuring it requires the use of instruments for each dimension of which it is composed. Physical activity as a method of intervention on children's quality of life is associated with children's physical as well as psychological well-being.

This review provides information about existing evidence of the benefits of physical activity for children's quality of life. Quality of life is a complex field characterised by multidimensionality; therefore, further investigation is needed to identify quantitative and qualitative evidence in order to consolidate the link between physical activity and its influence on children's quality of life. 


\section{BIBLIOGRAPHY}

[1] Bell, L. M., Watts, K., Siafarikas, A., Thompson, A., Ratnam, N., Bulsara, M., Finn, J., O’Driscoll, G., Green, D. J., Jones, T. W., \& Davis, E. A. (2007). Exercise alone reduces insulin resistance in obese children independently of changes in body composition. The Journal of Clinical Endocrinology \& Metabolism, 92(11), 4230-4235. https://doi.org/10.1210/jc.2007-0779

[2] Biddle, S. J. H., Ciaccioni, S., Thomas, G., \& Vergeer, I. (2019). Physical activity and mental health in children and adolescents: An updated review of reviews and an analysis of causality. Psychology of Sport and Exercise, 42, 146-155. https://doi.org/10.1016/j.psychsport.2018.08.011

[3] Casas, F. (2011). Subjective social indicators and child and adolescent well-being. Child Indicators Research, 4, 555-575. https://doi.org/10.1007/s12187-010-9093-Z

[4] Casas, F. (2007). Children's quality of life.

[5] https://www.childresearch.net/RESOURCE/RESEARCH/2007/exfile/CASAS.pdf

[6] Cummins, R. A. (2005). Moving from the quality of life concept to a theory. Journal of Intellectual Disability Research, 49(10), 699-706. https://doi.org/10.1111/j.1365-2788.2005.00738.x

[7] Diener, E., \& Suh, E. (1997). Measuring quality of life: Economic, social, and subjective indicators. Social Indicators Research, 40, 189-216. https://doi.org/10.1023/A:1006859511756

[8] Diener, E., Oishi, S., \& Lucas, R. E. (2003). Personality, culture, and subjective well-being: Emotional and cognitive evaluations of life. Annual Review of Psychology, 54, 403-425. https://doi.org/10.1146/annurev.psych.54.101601.145056

[9] European Union. (2015). Eurostat Statistical Books: Quality of life in Europe - Facts and views. Luxembourg: Publication Office of the European Union.

[10] Janssen, I., \& LeBlanc, A. G. (2010). Systematic review of the health benefits of physical activity and fitness in school-aged children and youth. International Journal of Behavioral Nutrition and Physical Activity, 7: 40. https://doi.org/10.1186/1479-5868-7-40

[11] Kirkcaldy, B. D., Shephard, R. J., \& Siefen, R. G. (2002). The relationship between physical activity and self-image and problem behaviour among adolescents. Social Psychiatry and Psychiatric Epidemiology, 37(11), 544-550. https://doi.org/10.1007/s00127-002-0554-7

[12] Kannus, P., Haapasalo, H., Sankelo, M., Sievänen, H., Pasanen, M., Heinonen, A., Oja, P., \& Vuori, I. (1995). Effect of starting age of physical activity on bone mass in the dominant arm of tennis and squash players. Annals of Internal Medicine, 123(1), 27-31. https://doi.org/10.7326/0003-4819-123-1-199507010-00003

[13] Marjanen, P., Ornellas, A., \& Mäntynen, L. (2017). Determining holistic child well-being: Critical reflections on theory and dominant models. Child Indicators Research, 10(3), 633-647. https://doi.org/10.1007/s12187-016-9399-6

[14] Mountjoy, M., Andersen, L. B., Armstrong, N., Biddle, S., Boreham, C., Brandl Bedenbeck, H.-P., Ekelund, U., Engebretsen, L., Hardman, K., Hills, A. P., Kahlmeier, S., Kriemler, S., Lambert, E., Ljungqvist, A., Matsudo, V., McKay, H., Micheli, L., Pate, R., Riddoch, C., ... van Mechelen, W. (2011). International Olympic Committee consensus statement on the health and fitness of young people through physical activity and sport. British Journal of Sports Medicine, 45(11), 839-848. https://doi.org/10.1136/bjsports-2011-090228

[15] Moeijes, J., van Busschbach, J. T., Wieringa, T. H., Kone, J., Bosscher, R. J., \& Twisk, J. W. R. (2019). Sports participation and health-related quality of life in children: Results of a crosssectional study. Health and Quality of Life Outcomes, 17: 64. https://doi.org/10.1186/s12955-019-1124-y

[16] Noll, H.-H. (2013). Subjective social indicators: Benefits and limitations for policy making An introduction to this special issue. Social Indicators Research, 114, 1-11. https://doi.org/10.1007/s11205-013-0379-7 
[17] Noll, H.-H. (2002). Towards a European system of social indicators: Theoretical framework and system architecture. In M. R. Hagerty, J. Vogel \& V. Møller (Eds.), Assessing quality of life and living conditions to guide national policy (pp. 47-87). Dordrecht: Springer. https://doi.org/10.1007/0-306-47513-8_4

[18] Petelewicz, M. (2015). The relationship between children's quality of life and the socioeconomic status of the family. The case of Lodz, Poland. Przeglad Socjologiczny, 64(1), 43-59.

[19] Pollard, E. L., \& Lee, P. D. (2003). Child well-being: A systematic review of the literature. Social Indicators Research, 61(1), 59-78. https://doi.org/10.1023/A:1021284215801

[20] Vella, S. A., Cliff, D. P., Magee, C. A., \& Okely, A. D. Sports participation and parentreported health-related quality of life in children: Longitudinal associations. The Journal of Pediatrics, 164(6), 1469-1474. https://doi.org/10.1016/j.jpeds.2014.01.071

[21] Vicente-Rodriguez, G., Jimenez-Ramirez, J., Ara, I., Serrano-Sanchez, J. A., Dorado, C., \& Calbet, J. A. (2003). Enhanced bone mass and physical fitness in prepubescent footballers. Bone, 33(5), 853-859. https://doi.org/10.1016/j.bone.2003.08.003

[22] Wallander, J. L., \& Koot, H. M. (2016). Quality of life in children: A critical examination of concepts, approaches, issues, and future directions. Clinical Psychology Review, 45, 131-143. $\underline{\text { https://doi.org/10.1016/j.cpr.2015.11.007 }}$

[23] The WHOQOL Group. (1995). The World Health Organization quality of life assessment (WHOQOL): Position paper from the World Health Organization. Social Science \& Medicin 